\title{
How To Design a Mobile Application to Enhance Teaching and Learning?
}

\author{
http://dx.doi.org/10.3991/ijet.v9i3.3507 \\ Dothang Truong \\ Embry Riddle Aeronautical University, Daytona Beach, FL, USA
}

\begin{abstract}
The rapid growth of mobile devices, especially smart phones, has changed the way instructors deliver instructions and students learn class materials. Many universities initiate promoting economic transformation by working to eliminate barriers to educational attainment through incorporating new technologies to enhance the delivery of instructions and student learning outcomes. The purpose of this research is to explore the usage of mobile applications in higher education and develop an application to help colleged students understand better the class materials, and thereby, enhance their learning outcomes. The detailed description, design, and interface of the application are presented along with dissemination plan.
\end{abstract}

Index Terms - higher education, mobile apps, flash card, learning outcomes, mobile devices

\section{INTRODUCTION}

In the networked era, mobile devices (smart phones, tablets) are growing and penetrating into everyone's life. Users use mobile devices for many purposes such as making phone calls, surfing the Internet, checking email, setting up work schedule in the calendar, making notes, watching movies and TV shows, listening to music, using GPS function, using utility applications, and playing games. These functionalities make mobile devices become so popular that someone believes mobile devices can actually replace laptops due to their sufficient functionalities and portability (Harkin, 2009; Dannen, 2010; Wood, 2011). Amongst mobile device providers, Apple is the pioneer and the sale leader with millions of sales for iPhone, iPod, and iPad. They also have the biggest application store for users.

College students represent one of the largest groups of mobile device users. They are very receptive to new technologies and are always among the first users of the latest model of mobile devices. The main question is that whether college students have used mobile devices to enhance their learning outcome. The answer for this question lies within the applications for those devices. While the hardware is upgraded every year to equip those devices with more advanced technologies, applications still lack of emphasis on student needs. Bestuniversities.com listed 100 best iPhone applications for college students emphasizing mainly on study help with foreign languages and math, newspaper sites, shopping deals, local guides, and reference. Only very few applications can help students in classroom but they are not free, and no application can be found for business students.

Recognizing the importance of technologies in the educational environment, many universities initiate (University of North Carolina Tomorrow Initiatives is a typical example) promoting economic transformation by working to eliminate barriers to educational attainment through incorporating new technologies to enhance the delivery of instructions and student learning outcomes. The purpose of this research is to incorporate mobile technologies in classroom to improve the teaching and learning at U.S. colleges. More specifically, we will develop a flashcard application for Apple iPhone with emphasis on helping business students to understand the class materials, and thereby, enhance their learning outcomes.

The research is structured as follows. Next section will provide a background about Apple mobile devices, its application store, University of North Carolina Tomorrow initiatives, and what applications are needed for college students in business programs. Then, we will describe the project and the design of the flashcard application. Results of the project will be described with detailed demonstration. Finally, dissemination plan, practical implications, and future research will be discussed.

\section{MOBILE DEVICES, APPLICATIONS, AND EDUCATIONAL ATTAINMENT}

\section{A. Mobile Devices and Applications}

A mobile device, also known as handheld device, is a pocket-sized computing device, typically having a display screen with touch input or a miniature keyboard. Smartphones and tablets are popular amongst those who require the assistance and convenience of a conventional computer, in environments where carrying one would not be practical. The mobile device market has been growing significantly with a very large number of smartphones and tablets in the market. These devices provide users with all features and functionalities necessary for business, study, and personal needs. Users can make phone calls, surf net, check and answer emails, set up calendar, listen to music, watch videos, prepare documents, chat with others, and play games. Typically these devices can provide almost everything you can get from a laptop with a much higher level of portability. In addition, the growing application stores allow users to use these devices to search for point of interest and direction, use the device as GPS in a car, search for Wifi spots, access library, organize business and/or study work, share information with others, update with latest news, check temperature, entertain with a variety of games and videos, and many other features.

Amongst mobile device providers, Apple is the leader. Apple overtook Microsoft Corp. to become the most valuable technology company on optimism (BusinessWeek, 2010). Apple provides three major mobile devices: iPhone, iPod Touch, and iPad. These devices are well known with the advanced touch screen technology and movement detection. It was reported that Apple had sold 33.8 million iPhones and 14.1 million iPads in the fourth quarter, 
that ended on September 28, of 2013 (Apple, 2013a). Apple application store is one of two largest application stores for mobile devices in the market. In September 2013, Apple announced that their application store has more 900,000 applications available with more than 50 billion downloads (Apple, 2013b). Users can run these applications in their iPod Touch, iPhone, and iPad. These numbers shows the significant impact of Apple mobile devices to our society. Amongst users, college students are very receptive to new technologies and always the ones who get the latest technologies in their hands. It can be seen that all college students own a mobile device and most of them own a smartphone or a PDA. The need of communicating, sharing knowledge, and creating relationships make college students one of the biggest market segments for mobile devices. The major question is how many percent of college students have used this technology to enhance their learning and what is the most effective way to incorporate this technology to teaching and learning.

\section{B. University of North Carolina Tomorrow Initiatives}

University of North Carolina (UNC) Tomorrow Initiatives is a typical example of educational efforts to eliminate barriers to educational attainment. Led by UNC President, UNC Tomorrow team examines how all of the campuses within the UNC System, including Carolina, will respond to the most pressing needs facing the state over the next 20 years. "The University of North Carolina is dedicated to the service of North Carolina and its people. In order to efficiently and effectively fulfill its threepronged mission of education, research and scholarship, and public c service in the 21 st century, the University should proactively anticipate and identify the needs facing our state over the next twenty years and, consistent with its mission, develop and implement responses to those needs." (UNC General Administration, 2007).

In order to follow UNC Tomorrow Initiatives, North Carolina universities have developed necessary steps to promote the economic transformation. One of the important recommendations is to promote economic transformation by working to eliminate barriers to educational attainment through enhancing the delivery of instruction by incorporating new technologies in teaching and learning. Along with this effort, this research aims at examining how mobile device applications can be developed in order to enhance the delivery of instruction. Since Apple is the leader in this market segment and they have the largest application store, we choose to focus on Apple applications (from now on it will be called Apple apps). Two major questions are: 1) Can Apple apps help enhance college teaching and learning?; 2) What type of Apple apps should be developed to help improve student learning outcomes, and therefore educational attainment?

\section{Mobile Apps and Educational Attainment}

Research shows that mobile devices promise a great potential in education (Thornton and Houser, 2004, 2005). Despite the popularity of Apple mobile devices in the college student population, only a few of U.S. institutions indicates the interest in incorporating this technology to teaching and learning. The most notable ones are Stanford University and University of Houston that offer iPhone apps courses to computer students (Bonsack, 2010; Bonnin, 2010). In North Carolina region, a group of computer science students, under advisement of computer profes- sors, developed an iPhone app that allows users to access faculty telephone numbers, campus map, and a course catalog (Fayetteville Observer, February 24, 2010). Although this is a good start, these initiatives are limited to offering new courses for computer majors and do not directly contribute to enhancing teaching and learning. For universities where student capabilities are wide spread and there is a large population of non-traditional students (military and military spouse students, working students), incorporating mobile technologies into teaching and learning is a vital step since this will help eliminate barriers to educational attainment.

Only a very few number of existing studies examine the role of smartphone apps in education enhancement. Young (2011) discusses several top smartphone apps that can improve teaching and research. In addition, Cummiskey (2011), Phillippi (2011), and White and Turner (2011) described how smartphone apps are used in health and physical education, nursing education, and computing education, respectively. In order to get a better understanding of smartphone apps in education, we check the Apple app store to examine apps that can be useful for college students. Bestuniversities.com listed 100 best Apple apps for college students emphasizing mainly on materials for foreign languages and math, newspaper sites, shopping deals, local guides, and reference. Only applications that seem to be helpful for students in classroom is homework application such as myHomework which allows students to organize their homework assignments and put them in the calendar and flash card applications which allow students to create study cards, view them, study them, and get score feedback. No particular applications aim at enhancing the delivery of instructions and student learning outcomes, especially in business areas. While students can easily find apps that help them learn foreign languages and remember math formulas, business students will have hard time to find apps for their fields. In business programs, students have to build a strong background in both quantitative and qualitative content. They will have to understand a tremendous number of terms from business law, accounting, economics, finance, statistics, management science, operations management, to strategic management, human resource management, entrepreneurship, and marketing. All courses in a curriculum are interrelated and concepts learned from prerequisite courses will be used as the ground for understanding concepts in following courses. Unfortunately, Apple apps do not provide such tools for business students.

To fill that gap, in this research we will develop and incorporate an Apple app in the teaching and learning process to enhance the delivery of instructions and student learning outcomes. First, we will look at some important categories of Apple educational apps that can be helpful for business students. Basically, Apple educational applications can be classified into four major categories: 1) flash card applications that provide students with the term, definition, explanation, formulas, and examples of all concepts in their study areas; 2) hands-on lecture and tutorial applications that show students step-by-step instructions; 3) utility applications that help students organize their study, provide curriculum guide, calculate GPA, and calculate the grades for each course; 4) interactive applications that allow students to communicate and work in a team without having to meet physically. 
Since Apple apps require extensive preparation and programming efforts in this research we choose to work on a flash card app for business majors. In order to ensure the contribution of this project we analyze existing flash card apps in Apple store. Table 1 summarizes existing flash card apps that are appropriate for college students. It appears that these apps share some common advantages. First, they are easy to navigate and simple to use, so students do not have any difficulties operating the app. Second, some of them allow users to create cards on the computer and download to their mobile device. Some others allow users to import cards from Quizlet and share with others. Third, most of them, but not all, provide the preview mode with score reports so students can keep track of their progress. On the other side, these apps also have some weaknesses. The first and important weakness is the lack of content. Most apps require users to create their own cards (directly in the device or import them from the computer). These apps will only be helpful for some short training or some special areas in which users need to study and create cards that they need. College students will not find these apps useful because they will not have time, especially non-traditional students or students who need academic help in HBCUs, to create a large pool of cards in all study areas. Some apps allow users to share their own cards or download from Quizlet. In the first sight, this method seems to solve that problem. However, flash cards on Quizlet (and on other similar websites) are also created by other users. This will raise an issue of the content accuracy and adequacy since there are no way students can check whether those cards are correct and sufficient. Some content may be pasted from the Internet without verification from professors in the field. Some content may be provided from the practical perspective (not textbook perspective) and will make students more confused in studying. Finally, there is still an insufficient amount of cards in business areas. A few of flash card apps provide available content for users, but mainly on foreign languages, US state information, and country demographic. The second weakness of these apps is that none of them are free. The price ranges from $\$ 0.99$ to $\$ 4.99$ per download. Although this seems to be a small investment, it still may create a barrier to students and some students may feel discouraged to use. There is a fact that some Apple apps turn out not exactly as they pretend to be and once users find out about disadvantages of the app, it is impossible for them to get their money back.

\section{RESEARCH DESIGN}

\section{A. Research description}

In order to answer the research questions and fill the gap in existing Apple flash card apps for college students this research aims at developing a flash card app that works with iPhone, iPod, and iPad. We will name this app "Business Study Flash Card" which does not exist in the Apple store. This is an important step to avoid any copyright issues. The app does not require the Internet connection and users can use it anywhere and anytime. The flash card application will contain class materials for business

TABLE I.

EXISTING FLASH CARD APPS IN THE APPLE STORE

\begin{tabular}{|c|c|c|c|}
\hline Application & Features and functionalities & Available content for users & Price \\
\hline FlashCard Touch & $\begin{array}{l}\text { Easy to use } \\
\text { Users can download cards from Quizlet } \\
\text { Add/edit function }\end{array}$ & $\begin{array}{l}\text { No available content } \\
\text { Users must develop their own cards }\end{array}$ & $\$ 4.99$ \\
\hline Flash of Genious & $\begin{array}{l}\text { Simple design } \\
\text { Users cannot add/edit cards } \\
\text { Does not mark right or wrong or provide scores }\end{array}$ & Available content on SAT vocabulary only & $\$ 0.99$ \\
\hline Flash Cards & $\begin{array}{l}\text { Users can add/delete cards and categorize them } \\
\text { Users can import cards from the Internet }\end{array}$ & $\begin{array}{l}\text { No available content } \\
\text { Users must develop their own cards }\end{array}$ & $\$ 2.99$ \\
\hline FlashCards Deluxe & $\begin{array}{l}\text { Provides cards by category } \\
\text { Easy to use } \\
\text { Users can customize cards } \\
\text { Users can back up the date in a computer }\end{array}$ & $\begin{array}{l}\text { Only available content are foreign languages, US } \\
\text { states, countries }\end{array}$ & $\$ 3.99$ \\
\hline iFlips Flash Cards & $\begin{array}{l}\text { Allows pictures and sound } \\
\text { Users can edit cards } \\
\text { Users can import cards from the Internet } \\
\text { Users can get cards from iFlipr.com }\end{array}$ & Only available content is foreign languages & $\$ 4.99$ \\
\hline FlashCard Pro & $\begin{array}{l}\text { Builds deck of cards } \\
\text { Users can import cards from the Internet } \\
\text { Checks and records scores }\end{array}$ & $\begin{array}{l}\text { No available content } \\
\text { Users must develop their own cards }\end{array}$ & $\$ 1.99$ \\
\hline Touch Cards 2 & $\begin{array}{l}\text { Users can import cards from other sources } \\
\text { Review mode } \\
\text { Provides statistics } \\
\text { Users can download cards from Quizlet } \\
\end{array}$ & $\begin{array}{l}\text { No available content } \\
\text { Users must develop their own cards }\end{array}$ & $\$ 1.99$ \\
\hline Flash Card Study & $\begin{array}{l}\text { Users can share cards with others } \\
\text { Users can customize font color, style } \\
\text { Allows highlight and image } \\
\text { Users can create cards on the website and import them } \\
\text { Provides study modes }\end{array}$ & $\begin{array}{l}\text { No available content } \\
\text { Users must develop their own cards }\end{array}$ & $\$ 3.99$ \\
\hline FlashCard Master & $\begin{array}{l}\text { Multiple choice mode } \\
\text { Score count } \\
\text { Users can import cards from website or computer }\end{array}$ & Only available content is foreign languages & $\$ 0.99$ \\
\hline FlashCard & $\begin{array}{l}\text { Users can add/delete cards } \\
\text { Preview modes }\end{array}$ & Only available content is foreign languages & $\$ 1.99$ \\
\hline
\end{tabular}

* source: Apple app store 
subjects. In this preliminary research, we include flash cards for two business subjects: management science and operations management. The application will be upgraded with more business subjects. Users can choose specific subject and view flash cards for that subject. What makes this app different from other flash card apps is that this app provides users, which are business students, with a comprehensive pool of flash cards in business subjects covering all important terms they need to learn in class. When a user selects a term, a question will be shown and the user will try to find the answer. After that the user clicks the Action button to see the right answer and mark Right or Wrong. The application will keep track with the number of Rights or Wrongs so the user knows his/her level of understanding. The user can delete unneeded card and add new cards to the pool.

Below are some advantages of this application compared to existing apps

- This application allows students to study new terms or concepts in any business subject or review terms and concepts they learn in class. Students will be able to search for the term they want or practice their understanding with those terms.

- This application is particularly helpful when students prepare for the exam or when they are in an upper division course and need to review terms and concepts introduced in previous courses. For quantitative or problem-based courses, formulas and examples are provided to help students understand the problem solving process.

- Students also have an option to add new terms and materials in an easy and convenient way.

- This application can run in iPhone, iPod, and iPad and does not require the Internet connection. Thus, it can reach a larger pool of users and allows them to use it anytime and anywhere.

- This application is totally free of charge with no banner adds (which could be very annoying sometimes)

\section{B. Research Design}

In order to provide users with above features and functionalities, the Business Study Flash Card app requires two major designs: user interface design and application structure design. Figure 1 shows the framework for the user interface design. The app will have three major views: main view, business subject view, and new card view. In the main view, which is the first view, when users click on the app icon in their mobile device they will see the app title, About Us button, and a button for each business subject. As they click About Us, they will see an introduction and important information about the app. As they select a certain business subject, they will be directed to the business subject view which shows cards for the selected subject. If they choose to view existing term, they just need to select the term. Only the term will be shown and in a question form and users will need to try to find the answer themselves first. After that, they can click the Action button to verify the answer. They will mark right or wrong for each term/question and the app will count the number of rights and/or wrongs. This will help users keep track of their progress. From the business subject view, they can choose to create a new card and they will be directed to the third view, the new card view. In this view, they can enter the new term/question and the answer.
Then they need to click Save to save the term or click Cancel to renter. They will be redirected to the business subject view to view the term/question. In this view, they can choose to delete a card by click the Trash icon.

The second component of the research design is the application structure design (Figure 2). This design will have three major view controllers: main view controller, business subject controller, and new card view controller. In addition, we will have database module and function module. Three view controllers include the user interface and codes that connect all actions to appropriate programming functions. The function module includes all programming functions for each action such as: switch views, show card, mark right, mark wrong, count right, count wrong, add card, delete card, save, cancel. These functions are written in Object $\mathrm{C}$ language. The database module includes the storage of question and answer for each business subject. When a new card is added and before users leave the app, all cards will be archived to the database. When users reenter the app, all cards will be unarchived from the database to show the latest status. All of these view controllers and modules interact with each other in proper algorithm to ensure the operation of the app.

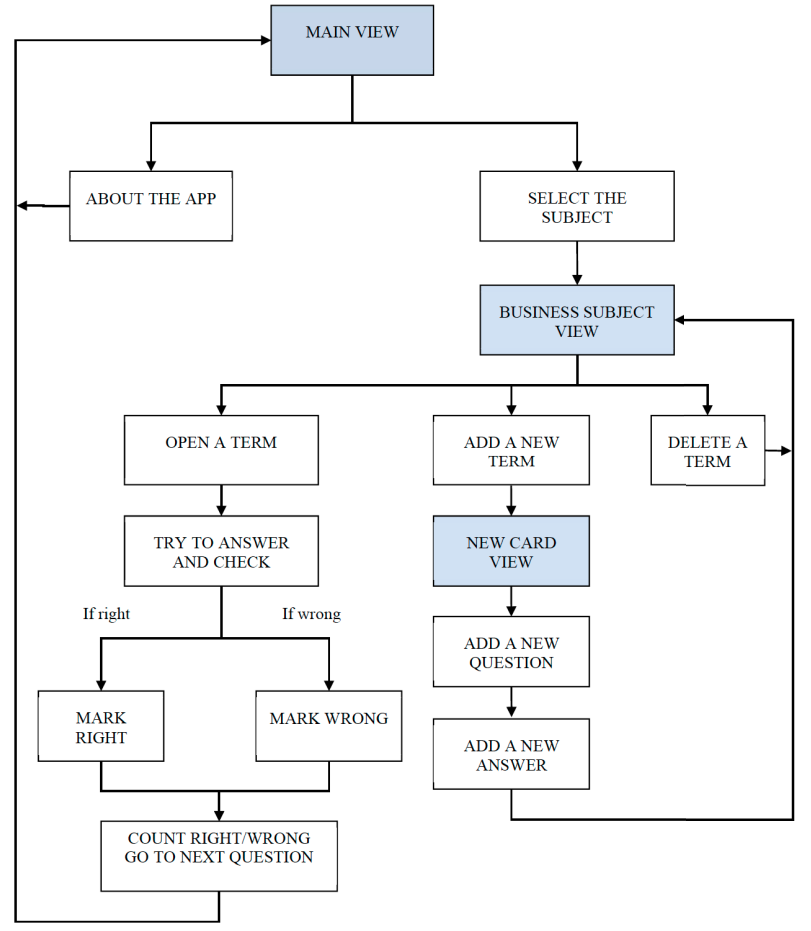

Figure 1. Business Study Flash Card - User Interface Model

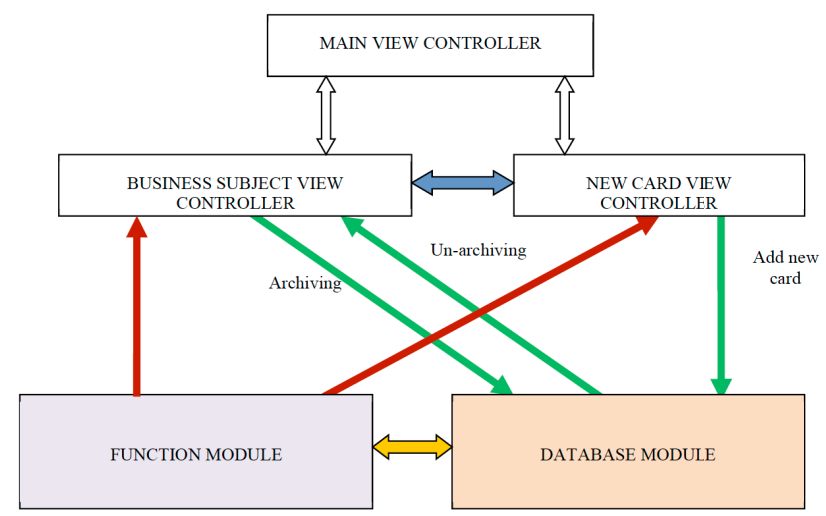

Figure 2. Business Study Flash Card - Application Structure Model 


\section{Research Requirements}

In order to make all of above features work, expertise, appropriate equipments and software, extensive interface design, algorithm, coding, and database management are required (Sadun, 2010).

- Apple apps work in the Mac environment, so a Macbook or iMac is required along with Snow Leopard OS 5.0 or higher.

- An Apple mobile device such as iPod Touch, iPhone, or $\mathrm{iPad}$ is required to test the app

- Software requirements: SDK 3.0 (Software Development Kit) which include Xcode, Cocoa Touch, and Objective C compiler; Adobe Photoshop

- Expertise with Mac environment, Snow Leopard OS 5.0, Objective C (object oriented language), Xcode, Cocoa Touch, Photoshop, iPhone simulation

\section{RESEARCH RESULTS, DEPLOYMENT AND DISSEMINATION PLAN}

\section{A. Research Results}

In this section, we will present the results of this research with the detail of Business Study Flash Card app. The app is fully functioning on the iPhone Simulator but it needs to be tested in a real mobile device such as iPhone or iPod Touch. In order to deploy this app to Apple store so users can download and use it with their mobile device there are more works to complete. Next section will discuss about requirements for this app deployment. The result demonstration is done using the snapshot of iPhone Simulator.

The app icon on iPhone screen: The icon uses the app logo which is developed by Adobe Photoshop. It is used to display the app in the device and in Apple store as well. Users can easily find this app by this unique icon (Figures 3 and 4.).

The main view: This is the first view that users will see when they enter the app. It shows the icon and three majors sub views: About Us, Management Science Cards, and Operations Management Cards. When users click on each button, the corresponding sub view will open (Fig. $5)$.

The About Us view: This view provides users with some introductions about the app. Due to the limited memory of mobile devices, it is suggested that we keep this view short and simple. An app logo also appears in here. The Back button allows users to go back to the main view (Fig. 6).

The business subject view: when users select a business subject (in this case we use Management Science subject), a sub view will open showing several actions. If there is no card in this subject, users will be asked to add a new one by clicking the Add button. At this time, other functions such as Delete, Mark Right, Mark Wrong, Action will be disabled (Fig. 7).

The new card view: When users click the Add button, a new view will open allowing them to enter new question and answer with the virtual keyboard of the device. If they make mistakes, they can click Cancel to reenter the content. This view is kept simple so users will not have any difficulties operating it (Figures 8 and 9).
The show card view: This view shows all existing cards and allows users to view them in different ways. The term/question will be displayed first and users need to click Action button (lower right corner) to see the answer. On the upper left corner, a label will show the card number and total number of cards in this subject. Users can also try to find the answer before clicking Action button and use Right or Wrong button to show their progress (this is optional). The number of rights or wrong will be displayed for users' information. Users can also delete the redundant card by clicking Delete button (trash icon). In order to go to next card, they just need to click Action button again. The Back button allows them to go back to the main view to select another subject (Figures 10 and 11).

\section{B. Requirements for Business Study Flash Card Deployment}

This app is fully functioning with described features and functionalities. However, this app is yet to be ready for the Apple app market. As with any other technological applications, this app requires some more tuning, revisions, and tests. As mentioned before, this app is developed and tested on iPhone Simulator, a component of Xcode platform. In order to make sure it works, the app must be tested in a real device such as iPhone or iPod Touch and some adjustment may need to be made because there are some differences between the simulator and real devices in term of memory capacity and smoothness of functions.

In addition, the complete database for those two business subjects must be developed and uploaded to the app. This step is very time consuming since there are a very large number of terms and concepts in those two subjects and we need to make sure we do not omit any important content. Another challenge with the database is the format compatibility. Apple apps work with a unique database format and this format is not compatible with other Window format such as Excel, Access (Sadun, 2010). The process of converting the database from a regular format to Apple accepted format will require some extensive programming work. Since business content is the major competitive advantage of this app, this process must be done carefully to ensure the smooth performance.

Another big challenge is memory management. Apple mobile devices have limited memory capacity and can handle only limited tasks at a time (Sadun, 2010). Any miscalculation or ineffectiveness in managing the database will result in a non-functioning or slow operating app. The memory management must be taken cautiously as we develop our database. The bigger the database the slower the app. Content such as images, audios, videos will slow the app significantly.

Finally, the author must apply to become Apple developer to be able to submit the app to Apple store. The app must meet all of their requirements and go through the entire review process and in order to appear in their app store. These processes usually take from two to six months depending on the reviewers' decision. The author also needs to continuously check, upgrade, fix any technical problems and perfect the app to enrich the content and attract more users. 
PAPER

How To Design a Mobile ApplicAtion to Enhance TeACHING AND LEARNing?

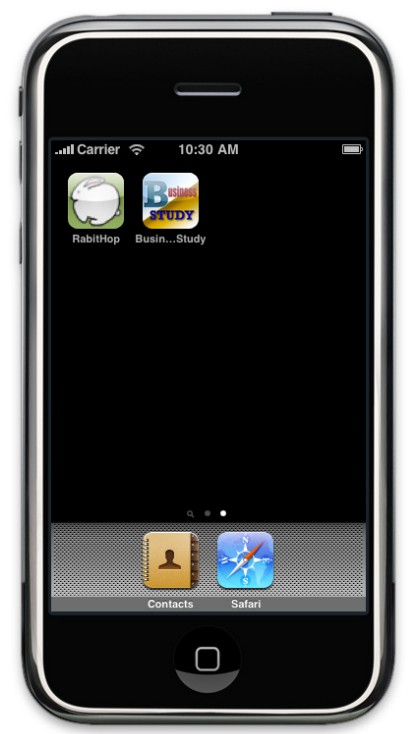

Figure 3.

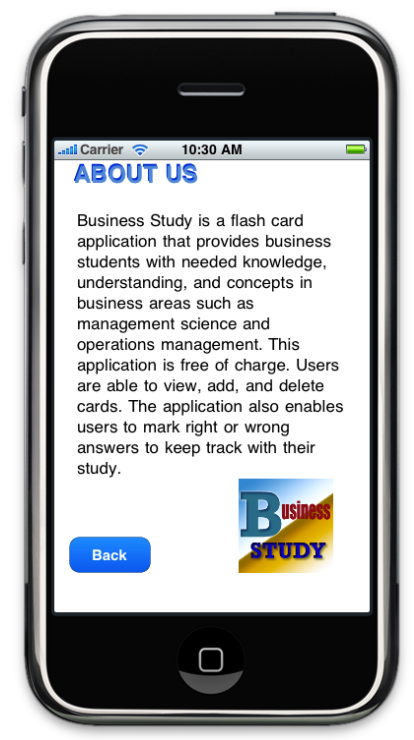

Figure 6.

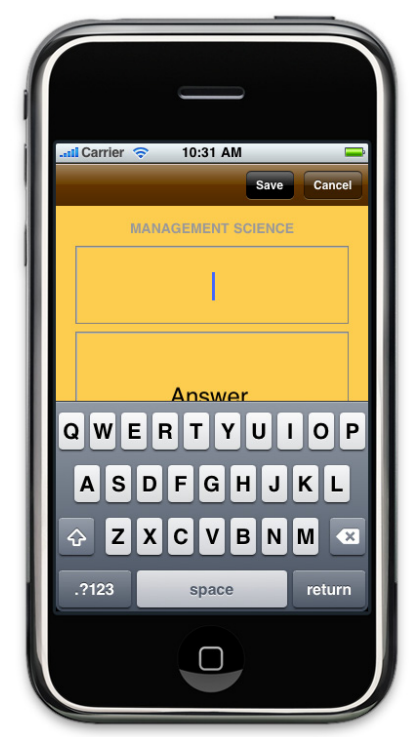

Figure 9.

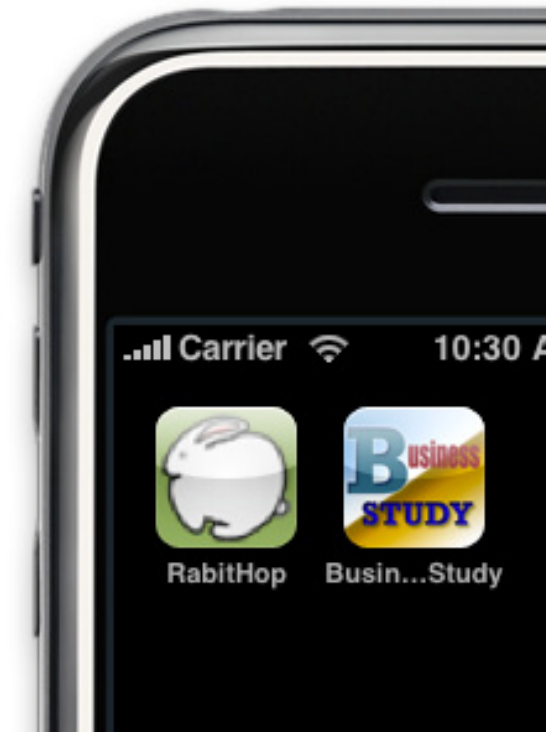

Figure 4 .

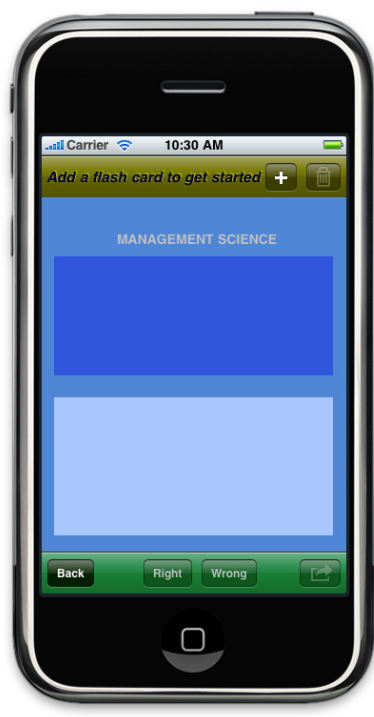

Figure 7.

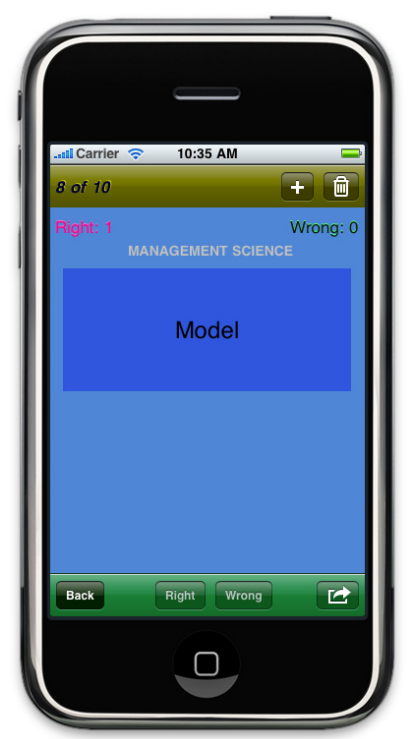

Figure 10.

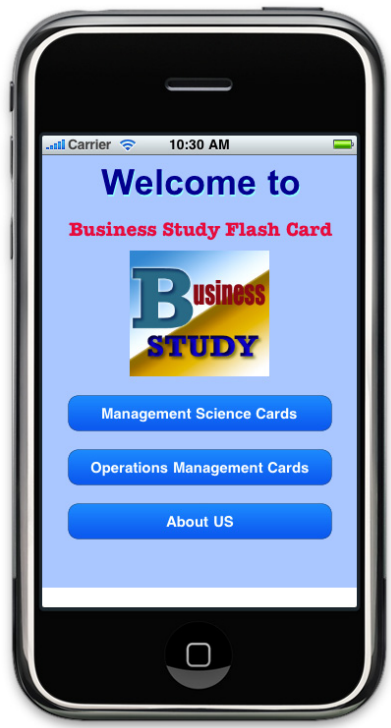

Figure 5 .

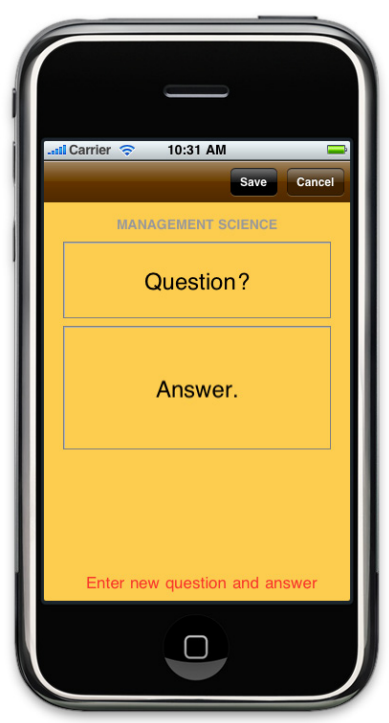

Figure 8.

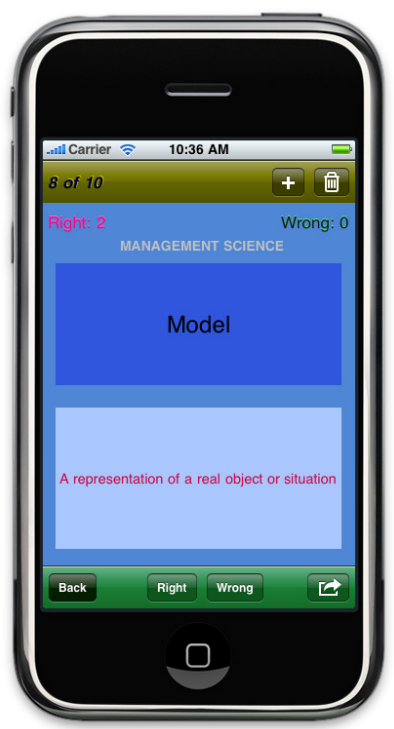

Figure 11. 


\section{Dissemination Plan}

Since the result of this project is vital to support initiatives in eliminating barriers to educational attainment, the results can be disseminated as follows

- The applications will be posted in Apple app store at a free of charge

- An email will be sent to business instructors and students in several universities and encourage them to use this application for teaching and learning

- The final report of this project will be posted in the university library

- We will keep track of the number of downloads and feedback from users.

- A follow up survey will be conducted to evaluate how this application enhances the delivery of instructions and student learning outcomes

\section{RESEARCH CONTRIBUTIONS}

As mobile devices grows significantly in our networked economy, it is important to examine how this technology can help enhance teaching and learning. This research has some major contributions. First, this is one of efforts to incorporate technologies in teaching and learning in order to eliminate barriers to educational attainment. This research recognizes the importance of mobile devices such as iPhone, iPod Touch, or iPad in the educational environment. For universities, this is an important initiative to help students enhance their learning outcome. The developed flash card app can be very helpful for students who need more helps to understand the subject and for nontraditional students who have to work full time or on duty. Using mobile devices they can study anywhere and anytime and review their understanding before the exam. If deployed properly, this app can contribute to increasing the retention rate. Second, this research fills the gap in existing study flash card apps in Apple store. All of existing cards are not free and do not target business students. In addition to having to pay for the app, students will have to create study cards by themselves. These barriers will most likely discourage students to use this useful tool for their class. This research will create a new initiative that will expand educational Apple apps with more features, functions, and conveniences for college students.

\section{RESEARCH LIMITATIONS AND FUTURE RESEARCH}

\section{A. Limitations}

For the scope of this research, the app still shows some limitations. It should be noted that these limitations associate with the fact that we attempt to keep the app simple and smooth functioning without any memory issues. First, the app only provides content for two business subjects; management sciences and operations management. Business students may expect to have more content for their areas in strategic management, accounting, finance, economics, management information systems, and marketing. Second, this app still lacks of a feature that allows students to download new cards from websites and share them with friends. However, this feature needs to be done with cautions because it may create issues with the accuracy of the content or database conflict that may mess up the current content. In addition, it will require Internet connect which could be a problem with iPod Touch or
iPad (non-3G model). Third, although this app provides formulas in a simple format it is yet to provide complex formulas. Apple development system does not allow entering mathematical formulas in an efficient way. Instead, for complex formulas we will need to embed them as images which will raise issues about the memory insufficiency. Finally, the app is yet to provide students with various preview modes such as search for term, view in order or randomly, and multiple choice format.

\section{B. Future Research}

Future research should focus on expanding the apps to all other business subjects and, at the same time, keep the app simple and smooth. Other features (as discussed in the previous section) could be added to attract more users. However, these attempts must be done with effective memory management to avoid any slowdown or breakdown of the app. In addition to flash card apps, more educational Apple apps should be developed such as hands-on lectures and tutorials in certain courses. These apps must be done separately for each course or even each module because this type of app requires more media content. Utility and interactive apps also can be developed to help students manage their study plan, keep track with their study progress, or work as a team with others.

\section{REFERENCES}

[1] Apple (2013a). Apple Reports Fourth Quarter Results. Apple Press Info, October 28. URL: http://www.apple.com/pr/ library/2013/10/28Apple-Reports-Fourth-Quarter-Results.html

[2] Apple (2013b). iOS 7 With Completely Redesigned User Interface \& Great New Features Available September 18. Apple Press Info, September 18. Retrieved from http://www.apple.com/pr/ library/2013/09/10iOS-7-With-Completely-Redesigned-UserInterface-Great-New-Features-Available-September-18.html

[3] Bonnin, R. (2010) iPhone Application Introduced at University of Houston, January 7, 2010. URL: http://www.uh.edu/newsevents/stories/2010articles/Jan2010/iPhone App Guide.php

[4] Bonsack, N. (2010) Stanford IPhone Development Course Returns for Winter 2010., PCWorld, January 14, 2010. URL: http://www.pcworld.com/article/186912/stanford_iphone_develop ment_course_returns_for_winter_2010.html

[5] Business Weeks (2010). Apple Overtakes Microsoft in Market Capitalization, Business Week News, May 26, 2010.URL: http://www.businessweek.com/news/2010-05-26/apple-overtakesmicrosoft-in-market-capitalization-update3-.html

[6] Cummiskey, M. (2011). There's an App for That Smartphone Use in Health and Physical Education. Journal of Physical Education, Recreation \& Dance, 82(8), 1-60. http://dx.doi.org/10.1080/07303084.2011.10598672

[7] Dannen, C. (2010). Why Your Phone Will Soon Replace Your Laptop. BNet, Mar 1, 2010. URL: http://industry.bnet.com/technology/10005659/why-your-phonewill-soon-replace-your-laptop/

[8] Fayetteville Observer (2010). UNC Pembroke students developed an iPhone app, February 24, 2010. URL: http://www.fayobserver.com

[9] Harkins, S. (2009). Can smartphones replace your clients' laptops and netbooks? TechnRepublic Blog, July 30th, 2009. URL: http://blogs.techrepublic.com.com/project-management/?p=820

[10] Phillippi, J. (2011) Smartphones in Nursing Education. Computers, Informatics, Nursing, 29(8), 449-454. http://dx.doi.org/10.1097/NCN.0b013e3181fc411f

[11] Sadun, E. (2010). The iPhone Developer's Cookbook: Building applications with the iPhone $3.0 \mathrm{SDK}, 2^{\text {nd }}$ edition. Addison Wesley.

[12] Thornton, P., and Houser, C. (2004). Using mobile phones in education. The 2nd IEEE International Workshop on Wireless and Mobile Technologies in Education Proceedings, 3-10. 
[13] Thornton, P., and Houser, C. (2005). Using mobile phones in English education in Japan. Journal of Computer Assisted Learning, 21(3), 217-228. http://dx.doi.org/10.1111/j.13652729.2005.00129.x

[14] UNC General Administrative (2007). University of North Carolina Tomorrow Commission Final Report. URL: http://www.northcarolina.edu/nctomorrow/reports/commission/Fin al_Report.pdf

[15] White, J., and Turner, H. (2011). Smartphone Computing in the Classroom. Pervasive Computing, IEEE, 10(2), 82-86. http://dx.doi.org/10.1109/MPRV.2011.33

[16] Wood, C. (2011). Mobile devices changing our world. Boulder County Business Report, 30(4), 22A-22A.

[17] Young, J.R. (2011). Top smartphone apps to improve teaching, research, and your life. Education Digest, 76(9), 12-15.

\section{AUTHOR}

Dothang Truong is an Associate Professor of Doctoral Studies at Embry Riddle Aeronautical University, Daytona Beach, FL 32114, USA. He is also a Certified Supply Chain Professional (CSCP). He has published a number of peer-reviewed articles in B2B e-commerce, supply chain management, cloud computing, and information management (e-mail: truongd@erau.edu)

This paper is the extended version of a conference proceeding presented at Decision Science Institute (DSI) Conference, November, 2012. Submitted 30 December 2013. Published as re-submitted by the author 05 April 2014. 